\title{
Research on Cutting Force of Turn-Milling Based on Thin-Walled Blade
}

\author{
Lida Zhu, ${ }^{1}$ Baoguang Liu, ${ }^{1}$ Xiaobang Wang, ${ }^{1,2}$ and Zhiwei Xu' ${ }^{1}$ \\ ${ }^{1}$ School of Mechanical Engineering and Automation, Northeastern University, Shenyang 110819, China \\ ${ }^{2}$ School of Mechanical Engineering and Automation, Dalian University of Technology, Dalian 116024, China
}

Correspondence should be addressed to Lida Zhu; zld1999@gmail.com

Received 18 February 2016; Revised 7 April 2016; Accepted 10 April 2016

Academic Editor: Massimiliano Barletta

Copyright (C) 2016 Lida Zhu et al. This is an open access article distributed under the Creative Commons Attribution License, which permits unrestricted use, distribution, and reproduction in any medium, provided the original work is properly cited.

Turn-milling is regarded as the milling of a curved surface while rotating the workpiece around its center point, which combines effectively the advantages of both turning and milling, wherein it allows for good metal removal with the difficult-to-cut thin-walled workpieces in aviation. The objective of the present work is to study cutting force by turn-milling in cutting condition. Aiming at the deformation properties of thin-walled blade, the predicted models of rigid cutting force and flexible cutting force with ball cutter are provided, respectively, in turn-milling process. The deformation values of blade and cutter are calculated, respectively, based on the engaged trajectory by using the iterative algorithm. The rigid and flexible cutting forces are compared and the influence degrees of cutting parameters on cutting forces are analyzed. These conclusions provide theoretical foundation and reference for turn-milling mechanism research.

\section{Introduction}

As a newly emerging cutting technology, turn-milling makes use of the advantages of turning and milling, in which both workpiece and cutting tool are given rotary motion simultaneously. The machining accuracy and processing efficiency are obtained by the advanced machining method. So it enjoys the advantages of turning and milling and excels at machining revolving workpieces, like crankshafts or camshafts. Actually, its strengths are far more than this. Owing to the intermittent cuts and simultaneous rotations of tools and workpieces, it keeps low thermal stresses, lowers cutting forces, and has good removal rates. With the rapid development of processing technology, the new machining techniques are well used to demand the requirements of product complexity and production of high-efficiency [1-3].

There are many researches on machining mechanism by turn-milling. Škorić et al. [4] have given an analysis of the suitability of turn-milling process. For the purpose of a comparative estimation of the process, a set of functions and methods are proposed and defined. The theoretical and real chip geometry is presented, respectively, in centric position and eccentric position. Pogacnik and Kopac in
[5] have described a complex kinematics process of this technology and the geometry of the tool and its position. In their study, practical data have formed a contrast of the roughness between the centric and eccentric turn-milling under different cutting parameters. Meanwhile, by their experimental work, it has been shown that there is a strong influence of vibration on turn-milling process. Finally, they have emphasized that turn-milling can lead to a better surface roughness and is much more suitable for cutting machining than turning. Choudhury and Bajpai in [6] and Choudhury and Mangrulkar in [7] have demonstrated by experiments that the surface roughness by orthogonal turn-milling rises with increase of cutter speed and lowers with increase of axial feed rate. This has also indicated that the roughness of orthogonal turn-milling is about ten times lower than that of turning. Moreover, the chips and surface quality of the former one are smaller and better than those of the latter one. By experiment techniques, some other experiments have been conducted to study the surface finish, in which mild-steel workpiece and high-speed steel cutting tools are employed. Besides, Calleja et al. in [8] have focused on the study of the optimal machining strategy for blades turn-milling. Different strategies and tilt angles have been tested. The proposed 
theoretical concepts have been applied in order to obtain the best turn-milling parameters for blades. Sava et al. in $[9,10]$ have found a cutting parameter optimization approach when machining cylindrical parts. This approach can lead to minimum surface roughness by using genetic algorithm in the tangential turn-milling process, during which the value of surface roughness can be easily controlled according to cutting parameters.

Biermann et al. [11] have proposed an FE model of the workpiece coupled with a geometric milling simulation for computing regenerative workpiece vibrations during the fiveaxis milling process. Lazoglu et al. [12] have predicted accurately the machining forces in high performance cutting of free form surfaces in aerospace, automotive, biomedical, and $\mathrm{die} / \mathrm{mold}$ industries and generalized approach for prediction of cutting forces in five-axis machining of parts with complex free form surfaces. Budak et al. [13-17] have proposed that the variable pitch cutters can be used to calculate cutting force in milling of these extremely flexible components. And then, they have studied the notion that the workpiece dynamics affect milling force in machining of flexible parts and presented a methodology for prediction of in-process workpiece dynamics based on a structural dynamic modification by using the FE model of the workpiece.

Herranz et al. in [18] have proposed a working methodology for efficient process planning, based on the previous analysis of those static and dynamic phenomena that may happen during high-speed cutting. This methodology includes (1) several steps in order to minimize the bending and vibration effects, (2) optimal monitoring methods to detect process instability, and (3) description of the best way for the tuning of cutting conditions and chip load, by means of simulation at different machining stages. In this paper, engine blade is complex thin-walled curved parts and plays an important part in the aerospace industry. Young's modulus of titanium is smaller, which is prone to distortion in the cutting process. If the cutting force is too large, it will cause large blade deformation and easily lead to poor quality, so machining error achieves processing requirements difficultly.

Olvera et al. in [19] have provided stiffness values for this type of machines clamping a common workpiece. To obtain this information an experimental methodology to measure static stiffness along kinematic chain of the turning center is proposed. Lamikiz et al. in [20] have presented assembly errors that are introduced as additional geometric parameters in the element transformation matrices, resulting in the real transformation matrix for a real and, therefore, imperfect five-axis milling machine. This matrix defines the real position of the tool in the absolute reference system. The predicted models of rigid and flexible cutting force with ball cutter are proposed, respectively, in turn-milling process in this paper. The deformation values of blade and cutter are calculated, respectively, by using the iterative algorithm. The accurate prediction of milling force will provide some theoretical foundations and references for choosing reasonable tools. So the cutting force prediction can provide critical guidance for the cutting parameters optimization.

This paper is divided into four main sections. The first, entitled The Principle of Turn-Milling Blades, will introduce

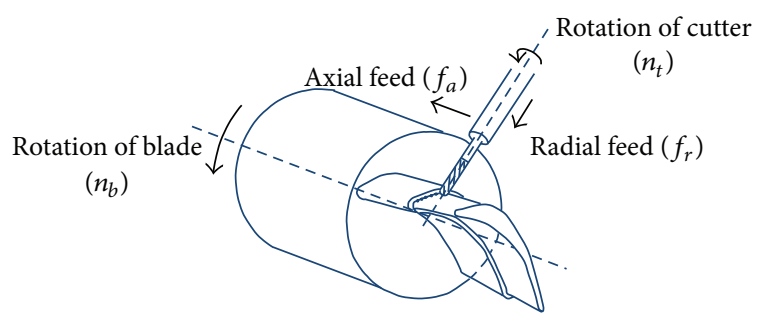

FIGURE 1: Turn-milling blade principle diagram.

the basic motions in turn-milling process. The second section, Rigid Cutting Force Model and Main Parameters, will consider the influence of ball-end cutter and cutting parameters on cutting force. The third part, Flexible Cutting Force Model, will consider the influence of flexibility deformation on cutting force by the iterative algorithm and identification of cutting force coefficients. The next part, Simulation Analysis of Ball-End Cutting Force, will compare rigid and flexible cutting forces and analyze the influence degree of main cutting parameters on the cutting forces. Finally, some conclusions from this study are given.

\section{The Principle of Turn-Milling Blades}

Turn-milling involves four basic motions including rotation of cutter, rotation of workpiece, axial feed, and radial feed of cutter, as shown in Figure 1. Milling blade is not simply the turning and milling processing methods into a single machine for processing blade, but the use of turn-milling motion to accomplish complex surface machining blades. The main cutting motion is the rotary motion of ball milling; the speeds of ball milling rotation and blades rotation together determine the cutting speed. The rotational speed of ball cutter plays a dominated role in the whole cutting process, so the rotation speed of the blade is even ignored in high-speed and super-speed process.

The complex surface of the blade is engaged by using the composite turn-milling motion. It can be seen that, during each cutting period, several cutting inserts are in contact with the workpiece at the same time, so intermittent cutting and enough quenching time for each cutting edge can be gained. So machining heat transfers more to chips, resulting in low workpiece temperature, little thermal deformation, high surface finish, and small tool wear. Meanwhile, good chip removal rate and automatic chip disposal can also be achieved, because of the short chips produced in turnmilling.

\section{Rigid Cutting Force Model and Main Parameters}

In turn-milling, cutting forces depend on the instantaneous uncut chip thickness. Hence, accurate calculation of chip thickness is quite critical for turn-milling cutting force predictions. The uncut chip thickness can be quite complicated since the tool can rotate as well as translate within a tool path segment. The geometry model of ball-end mill 


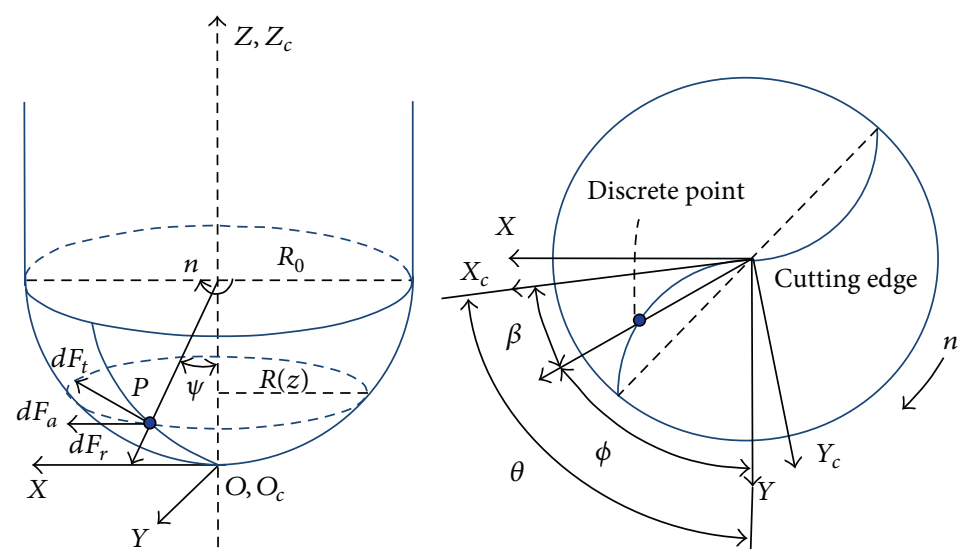

FIGURE 2: Geometry model of the ball-end mill.

and cutting forces in differential direction are shown in Figure 2. The three coordinates are established in the model, including machine coordinate $(X, Y, Z)$, the tool coordinate $\left(X_{c}, Y_{c}, Z_{c}\right)$, and the blade coordinate $\left(X_{b}, Y_{b}, Z_{b}\right)$. Assume $P$ is the random point on the cutting edge and $C$ is the center of the ball-end mill tip. For a differential chip load in the engagement domain, the differential cutting forces in radial, axial, and tangential direction are written as follows [10]:

$$
\begin{aligned}
& d F_{r}=K_{r c} \cdot\left(t_{c} \cdot d z\right)+K_{r e} \cdot d z, \\
& d F_{a}=K_{a c}\left(t_{c} \cdot d z\right)+K_{a e} \cdot d z, \\
& d F_{t}=K_{a c} \cdot\left(t_{c} \cdot d z\right)+K_{t e} \cdot d z .
\end{aligned}
$$

The effects of the lead and tilt angles on the cut geometry have to be considered in curve machining. Consider two fluted ball-end mills where one of the cutting flutes is aligned with the $X$-axis. The angle between the $Y$-axis and the reference cutting flute is represented as the reference rotation angle. The rotation angle is the angle between the cross-feed direction and the cutting flutes [12].

In order to obtain the transformation from the coordinate frame to feed coordinate, cutting forces in rotating dynamometer coordinate frame are calculated from the following transformations:

$$
\left[\begin{array}{l}
d F_{x} \\
d F_{y} \\
d F_{z}
\end{array}\right]=\left[\begin{array}{ccc}
-\sin (\psi) \times \sin (\phi) & -\cos (\psi) \times \sin (\phi) & -\cos (\phi) \\
-\sin (\psi) \times \cos (\phi) & -\cos (\psi) \times \cos (\phi) & \sin (\phi) \\
\cos (\psi) & -\sin (\psi) & 0
\end{array}\right]\left[\begin{array}{ccc}
\cos (\beta+\theta) & -\sin ((\beta+\theta)) & 0 \\
\sin (\beta+\theta) & \cos (\beta+\theta) & 0 \\
0 & 0 & 1
\end{array}\right]\left[\begin{array}{l}
d F_{r} \\
d F_{a} \\
d F_{t}
\end{array}\right]
$$

\section{Flexible Cutting Force Model}

Flexible cutting force method considers not only the feedback effect of tool-workpiece deformation on engagement zone, but also the impact of various modifications and coupling effects due to the change in stiffness of the workpiece material removal, which is used in thin-walled components. The blade is regarded as a workpiece, of which the thickness is equivalent to the size of the deformed thin-walled parts.

4.1. Iterative Correction of Actual Cutting Depth. It is important that the direction to the contact between tool and part is variable with feed of tool and position of blade, so the cutting forces are variable in different directions. Since the elastic deformation of tool and workpiece in the interaction force, the displacements occur in the opposite directions, and the actual cutting capacity (such as the radial depth of cut) is not equal to the nominal value of the design. Surface error $e_{t b}$ at any point of the surface generated can be expressed as follows:

$$
e_{t b}=\delta_{t}+\delta_{b}
$$

In a transient of milling, the actual chip thickness of cutter node $(i, j)$ is smaller than the calculated nominal value. Within next cycles, the additional amount left by cutter node $(i, j)$ will be cut by cutter node $(i+1, j)$ and so forth. After the cutter period of rotation, the instantaneous undeformed chip thickness converges to the results calculated based on notional amount of a single tooth feed. So the actual radial depth of cut can be given as follows:

$$
a_{e}^{(k+1)}(i, j)=a_{e}-\left[\delta_{t}^{(k)}(i, j)+\delta_{b}^{(k)}(i, j)\right]
$$

4.2. Deformation Calculation of Tool. The horizontal direction component is a major factor of the cutter deflection and the cutter clamping deflection. Although vertical force is also acting on the cutter, the axial deflection of tooling system is usually ignored resulting from the stiffness in the 


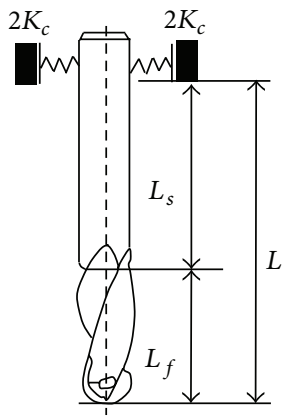

(a) Ball-end milling bending system (b) Simplified into a ladder cylindrical cantilever beam

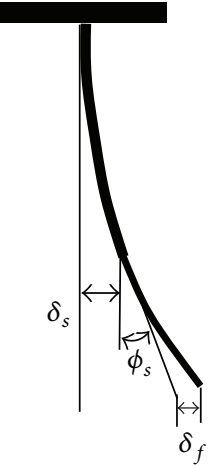

FIGURE 3: Bending model of ball-end milling.

axial direction which is relatively high. Consequently the deflection in the cutting system can be expressed as [21]

$$
\delta_{t}=\delta_{w}+\delta_{c}
$$

As a cantilever beam tool, the tool bending deflection $\delta_{w}$ can be expressed as follows:

$$
\begin{aligned}
& \delta_{w} \\
& \quad=\frac{F}{6 E I}\left\{\left(z_{F}-z\right)^{3}-(L-z)^{3}+3(L-z)^{2}\left(L-z_{F}\right)\right\},
\end{aligned}
$$

where $F$ is the cutting force; $I$ is the area moment of inertia of the cutter; $E$ is Young's modulus; $L$ is the overhand; $z_{F}$ is the $z$-directional position of the applied force; and $z$ is the position of the deflection.

As shown in Figure 3, the clamping deflection at shank clamping $\delta_{c}$ can be expressed as follows [22]:

$$
\begin{aligned}
\delta_{c} & =\delta_{s}+\delta_{f}+\phi_{s}\left(L_{f}-z\right) \\
& =\frac{F}{6 E I}\left\{-\left(L-L_{f}\right)^{3}+3\left(L-L_{f}\right)^{2}\left(L-z_{F}\right)\right\} \\
& +\frac{F}{6 E I_{f}}\left\{\left(z_{F}-z\right)^{3}-(L-z)^{3}+3(L-z)^{2}\left(L-z_{F}\right)\right\} \\
& +\frac{F}{2 E I}\left\{-\left(L-L_{f}\right)^{2}+2\left(L-L_{f}\right)\left(L-z_{F}\right)\right\} \\
& \cdot\left(L_{f}-z\right),
\end{aligned}
$$

where $\delta_{s}$ is deflection of the shank; $\delta_{f}$ is deflection of the flute; $\phi_{s}$ is deflection angle of the shank; $L_{f}$ is length of the flute; and $I_{f}$ is the moment of inertia relative to shaped mandrel of cutter edge section.

To calculate the clamping deflection, an experiment needs to be done to get the stiffness at clamping:

$$
\delta_{c}=\frac{F}{K_{c}} .
$$

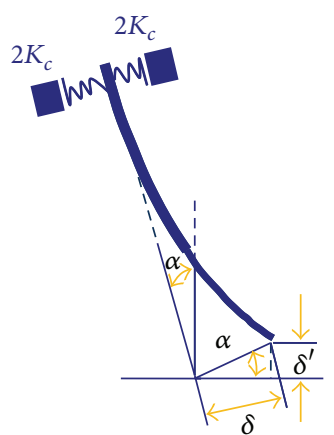

Figure 4: Actual deformation in processing of ball-end milling.

Then the ball-end milling horizontal offset can be given as follows:

$$
\begin{aligned}
\delta_{t} & =\frac{F_{C}}{6 E I}\left\{-\left(L-L_{f}\right)^{3}+3\left(L-L_{f}\right)^{2}\left(L-z_{F}\right)\right\} \\
& +\frac{F_{C}}{6 E I_{f}}\left\{\left(z_{F}-z\right)^{3}-(L-z)^{3}+3(L-z)^{2}\left(L-z_{F}\right)\right\} \\
& +\frac{F_{C}}{2 E I}\left\{-\left(L-L_{f}\right)^{2}+2\left(L-L_{f}\right)\left(L-z_{F}\right)\right\} \\
& \cdot\left(L_{f}-z\right)+\frac{F_{C}}{K_{c}}
\end{aligned}
$$

where $F_{C}=F_{x} \sin \phi+F_{y} \cos \phi$ and $z_{F}$ is given as follows:

$$
z_{F}=r-r \sin \left(\frac{\pi}{2}-\alpha-\frac{1}{2} \arccos \frac{R-a_{p}}{R}\right) .
$$

The surface form error is usually defined as a distance between the nominal surface and the machined one in the direction of the surface normal. From the calculated horizontal deflection, due to the lead and tilt angles in Figure 4 , the surface form error normal to the surface can be calculated as

$$
e=\delta \cdot|\sin \alpha| .
$$

4.3. Deformation Calculation of Blade. In the process of milling blades, the force on the vertical direction of blade surface will be produced, which produces bending deformation of blades while making the tool bend. Since the blades are thin-walled workpiece, its thickness has a great influence on the deformation.

The slope angle of each point is equal to rotation angle of the rotating coordinate system required in the next step as shown in Figure 5. As a result, $a_{b}$ (rotation angle of system $X_{1} O Y_{1}$ ) and $a_{s}$ (rotation angle of system $X_{2} O_{2}$ ) can be expressed as follows:

$$
\begin{aligned}
\alpha_{b} & =\arctan k_{b} \\
& =\arctan \left(a_{1}+2 a_{2} x+3 a_{3} x^{2}+4 a_{4} x^{3}+5 a_{5} x^{4}\right), \\
\alpha_{s} & =\arctan k_{s} \\
& =\arctan \left(b_{1}+2 b_{2} x+3 b_{3} x^{2}+4 b_{4} x^{3}+5 b_{5} x^{4}\right) .
\end{aligned}
$$




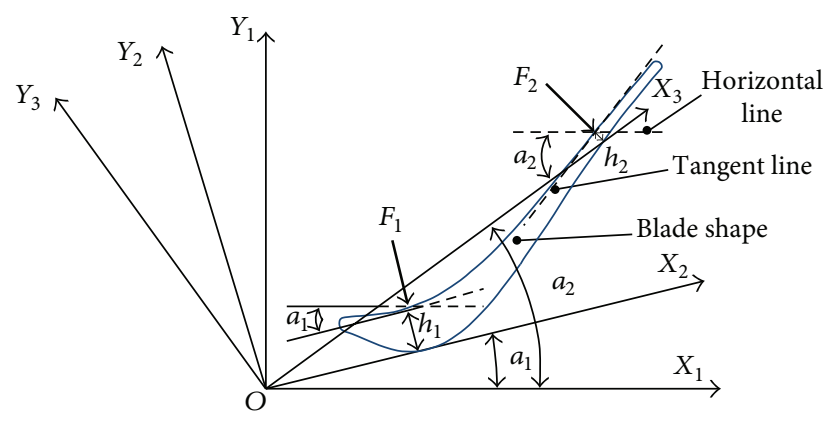

FIGURE 5: Instantaneous thickness in blade machining.

The equations of blade basin and back of blade are expressed, respectively, as follows:

$$
\begin{aligned}
x_{b} & \\
= & x \cos a_{b} \\
& +\left(a_{0}+a_{1} x+a_{2} x^{2}+a_{3} x^{3}+a_{4} x^{4}+a_{5} x^{5}\right) \sin a_{p}, \\
y_{b} & \\
= & \left(a_{0}+a_{1} x+a_{2} x^{2}+a_{3} x^{3}+a_{4} x^{4}+a_{5} x^{5}\right) \cos a_{p} \\
& -x \sin a_{p}, \\
x_{s} \quad & \\
= & x \cos a_{s} \\
& +\left(b_{0}+b_{1} x+b_{2} x^{2}+b_{3} x^{3}+b_{4} x^{4}+b_{5} x^{5}\right) \sin a_{s}, \\
y_{s} \quad & \\
= & \left(b_{0}+b_{1} x+b_{2} x^{2}+b_{3} x^{3}+b_{4} x^{4}+b_{5} x^{5}\right) \cos a_{s} \\
& -x \sin a_{s} .
\end{aligned}
$$

For any cutting points, the value of instantaneous thickness is calculated as follows:

$$
\begin{aligned}
& h_{b}=\left.y_{b}\right|_{x_{b}}-\left.y_{s}\right|_{x_{s}}, \\
& h_{s}=\left.y_{b}\right|_{x_{s}}-\left.y_{s}\right|_{x_{s}} .
\end{aligned}
$$

The instantaneous blade thickness curve can be obtained as shown in Figure 6. Based on the formula the instantaneous stiffness on the point of cutter can be obtained:

$$
k=\frac{E h^{3}}{12\left(1-v^{2}\right)} \text {. }
$$

The instantaneous stiffness is obtained based on (16). It can be seen from Figure 7 that stiffness of the cutting point at the ends of the airfoil is relatively small while the local stiffness of the thicker intermediate is larger. Using the curved thin plate reciprocal theory, solution of the problem can be obtained.

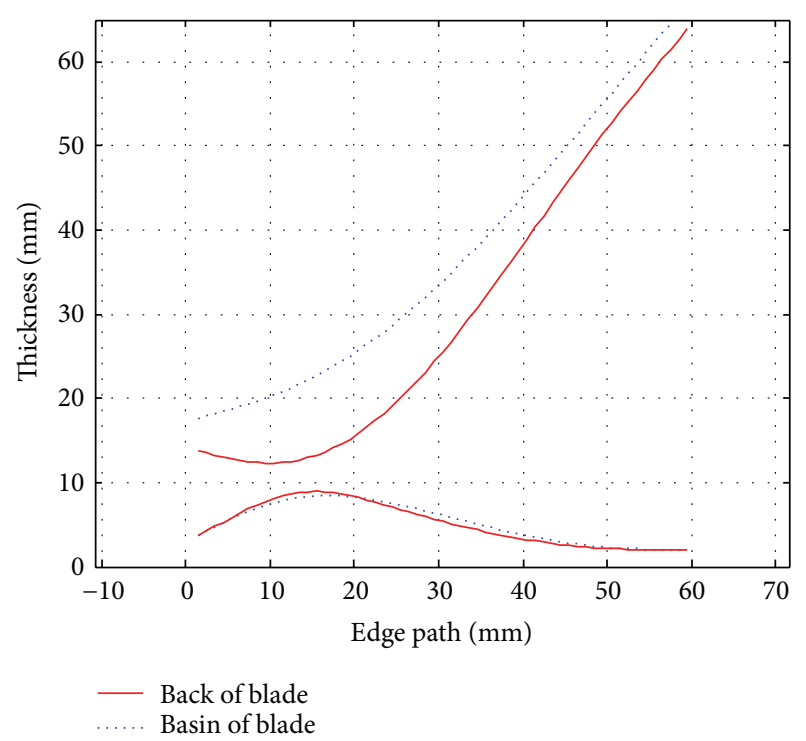

FIGURE 6: Instantaneous blade thickness curve.

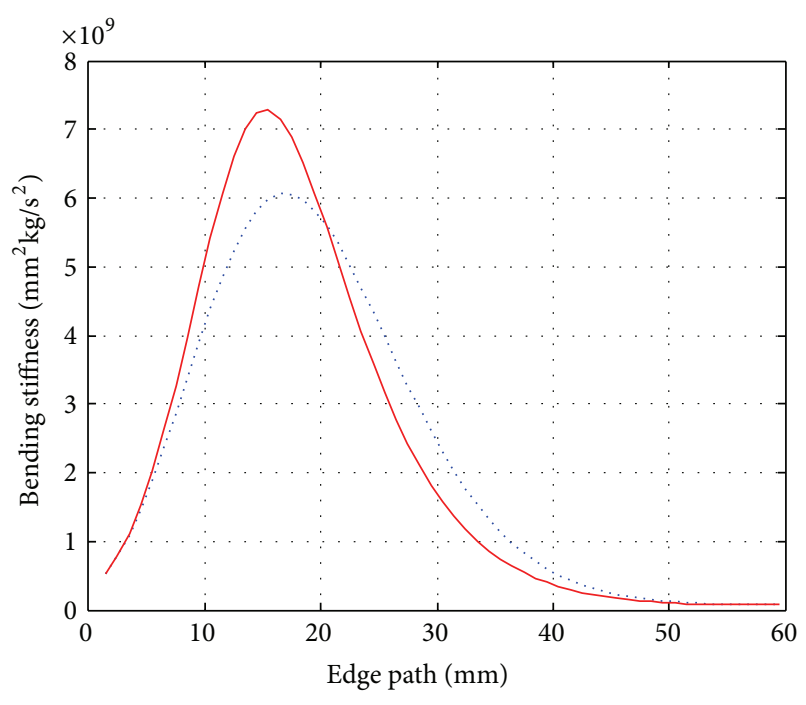

Back of blade

Basin of blade

FIGURE 7: Instantaneous stiffness on the point of cutter.

\subsection{Identification of Cutting Force Coefficients}

4.4.1. Cutting Coefficients Model. In order to calculate the cutting forces, the edge-specific coefficients and the shearspecific coefficients need to be obtained beforehand, which are determined by materials and geometry of tool and workpiece. In the research, proposed by Cao et al., these coefficients are obtained from the experiments using the planar surfaces [23]. The coefficients can be calculated by

$$
\begin{aligned}
K_{t c} & =\frac{2 \pi}{N A_{1}} \cdot \frac{C_{3} \bar{F}_{x c}-\left(C_{2}-C_{1}\right) \bar{F}_{y c}}{C_{3}^{2}+\left(C_{2}-C_{1}\right)^{2}}, \\
K_{r c} & =\frac{2 \pi}{N\left(A_{2}^{2}+A_{3}^{2}\right)}
\end{aligned}
$$




$$
\begin{aligned}
& \cdot\left[\frac{A_{2}\left(C_{2}-C_{1}\right) \bar{F}_{x c}+C_{3} \bar{F}_{y c}}{C_{3}^{2}+\left(C_{2}-C_{1}\right)^{2}}-\frac{A_{3} \bar{F}_{z c}}{C_{5}}\right], \\
K_{a c}= & \frac{2 \pi}{N\left(A_{2}^{2}+A_{3}^{2}\right)} \\
& \cdot\left[\frac{A_{3}\left(C_{2}-C_{1}\right) \bar{F}_{x c}+C_{3} \bar{F}_{y c}}{C_{3}^{2}+\left(C_{2}-C_{1}\right)^{2}}+\frac{A_{2} \bar{F}_{z c}}{C_{5}}\right], \\
K_{t e}= & \frac{-2 \pi}{N B_{1}} \cdot \frac{C_{4} \bar{F}_{x e}+C_{5} \bar{F}_{y e}}{C_{4}^{2}+C_{5}^{2}}, \\
K_{r e}= & \frac{2 \pi}{N\left(B_{2}^{2}+B_{3}^{2}\right)} \\
& \cdot\left[\frac{B_{2}\left(C_{5} \bar{F}_{x e}-C_{4} \bar{F}_{y e}\right)}{C_{4}^{2}+C_{5}^{2}}+\frac{B_{3} \bar{F}_{z e}}{2 C_{1}}\right], \\
K_{r e}= & \frac{2 \pi}{N\left(B_{2}^{2}+B_{3}^{2}\right)} \\
& \cdot\left[\frac{B_{3}\left(C_{5} \bar{F}_{x e}-C_{4} \bar{F}_{y e}\right)}{C_{4}^{2}+C_{5}^{2}}-\frac{B_{2} \bar{F}_{z e}}{2 C_{1}}\right],
\end{aligned}
$$

where $A_{i}, B_{i}$, and $C_{i}(i=1,2,3,4,5)$ are the parameters associated with start and exit radial immersion angles $\varphi_{\text {st }}$ and $\varphi_{\mathrm{ex}}$ and with two boundaries of the position angles $\theta_{\text {min }}$ and $\theta_{\max } ; \bar{F}_{q c}$ and $\bar{F}_{q e}(q=X, Y, Z)$ are the average cutting force components for different inclination angles and could be obtained from following cutting tests.

The relationship among them is shown as the following: the details of the numerical procedure of computing parameters are available in [23].

$$
\text { Where } d s(\theta)=\left|d p\left(X_{C}, Y_{C}, Z_{C}\right)^{T}\right|=
$$
$\sqrt{\left(X_{C}^{\prime}\right)^{2}+\left(Y_{C}^{\prime}\right)^{2}+\left(Z_{C}^{\prime}\right)^{2}} d \theta$ is the length of each differential element of the cutting edge, $\left(X_{C}, Y_{C}, Z_{C}\right)$ is the arbitrary point on the cutting edge. Consider

$$
\begin{aligned}
& A_{1}=\int_{\theta_{\min }}^{\theta_{\max }} R \sin \theta d \theta, \\
& A_{2}=\int_{\theta_{\min }}^{\theta_{\max }} R \sin \theta^{2} d \theta, \\
& A_{3}=\int_{\theta_{\min }}^{\theta_{\max }} R \sin \theta \cos \theta d \theta, \\
& B_{1}=\int_{\theta_{\min }}^{\theta_{\max }} d s(\theta), \\
& B_{2}=\int_{\theta_{\min }}^{\theta_{\max }} \sin \theta d s(\theta), \\
& B_{3}=\int_{\theta_{\min }}^{\theta_{\max }} \cos \theta d s(\theta),
\end{aligned}
$$

TABLE 1: Main parameters of machining center.

\begin{tabular}{lc}
\hline Control system & $\begin{array}{c}\text { FANUC-OI (MC) } \\
\text { control system }\end{array}$ \\
\hline Maximum spindle speed & $6000 \mathrm{r} / \mathrm{min}$ \\
Stroke $(X / Y / Z)$ & $850 \mathrm{~mm} / 500 \mathrm{~mm} / 630 \mathrm{~mm}$ \\
Spindle maximum torque & $70 / 909($ continuous $/ 30 \mathrm{~min}) \mathrm{N} . \mathrm{M}$ \\
Maximum fast feed speed & $X$ and $Y 24 \mathrm{~m} / \mathrm{min} ; Z 15 \mathrm{~m} / \mathrm{min}$ \\
Maximum working load & $500 \mathrm{~kg}$ \\
Power & $11 / 7.5 \mathrm{KW}$ \\
\hline
\end{tabular}

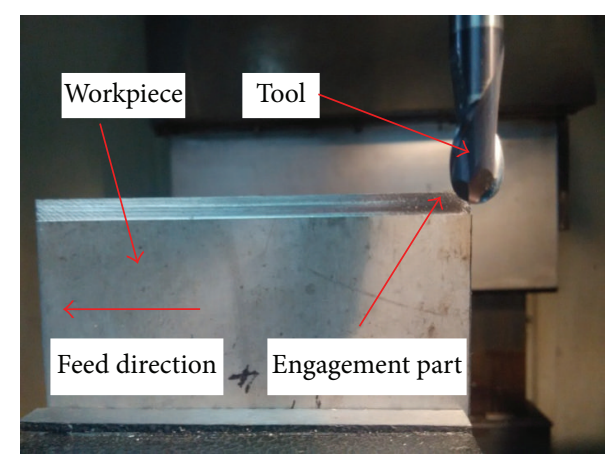

FIGURE 8: TH5650 vertical machining center.

$$
\begin{aligned}
& C_{1}=\left.\frac{1}{2} \varphi\right|_{\varphi_{\mathrm{st}}} ^{\varphi_{\mathrm{xt}}}, \\
& C_{2}=\left.\frac{1}{4} \sin 2 \varphi\right|_{\varphi_{\mathrm{st}}} ^{\varphi_{\mathrm{ex}}}, \\
& C_{3}=\left.\frac{1}{4} \cos 2 \varphi\right|_{\varphi_{\mathrm{st}}} ^{\varphi_{\mathrm{ex}}}, \\
& C_{4}=\left.\sin \varphi\right|_{\varphi_{\mathrm{st}}} ^{\varphi_{\mathrm{st}}}, \\
& C_{5}=\left.\cos \varphi\right|_{\varphi_{\mathrm{st}}} ^{\varphi_{\mathrm{x}}} .
\end{aligned}
$$

4.4.2. Cutting Force Coefficient Identification Test. Experimental cutting force coefficient identification was conducted using the TH5650 vertical machining center (Figure 8). The material used for the machining tests was Ti-6Al-4V (TC4) alloy. A three-component Kistler dynamometer type Kistler 9257B (Figure 9) has been mounted on the machine table and the coordinates system has been set to level with the force sensor surfaces. The tool has been chosen to ensure stable depth of cut in milling; a two-flute cutter with $10 \mathrm{~mm}$ diameter has been selected and mounted with $20 \mathrm{~mm}$ overhang on an HSK32ER20 tool-holder. The main parameters of the machine are as in Table 1.

In this experiment, the cutting tool is a hard alloy material of the ball-end mill; the milling cutter helix angle is 30 degrees, whose diameter is $10 \mathrm{~mm}$. Selection of milling parameters is as follows: spindle speed $300 \mathrm{r} / \mathrm{min}$, each tooth feed $(0.02,0.04,0.06) \mathrm{mm} / z$, and axial cutting deep $(1,2$, 3) $\mathrm{mm}$. 
TABLe 2: Milling test data.

\begin{tabular}{|c|c|c|c|c|c|c|}
\hline Test ID & $\begin{array}{c}\text { Spindle speed } \\
n(\mathrm{r} / \mathrm{min})\end{array}$ & $\begin{array}{l}\text { Feed per } \\
\text { tooth } \\
c(\mathrm{~mm} / z)\end{array}$ & $\begin{array}{c}\text { Axial cutting } \\
\text { depth } \\
a_{p}(\mathrm{~mm})\end{array}$ & $\begin{array}{c}X \text { axial } \\
\text { periodic force } \\
F_{x}(\mathrm{~N}) \\
\end{array}$ & $\begin{array}{c}Y \text { axial } \\
\text { periodic force } \\
F_{y}(\mathrm{~N})\end{array}$ & $\begin{array}{c}Z \text { axial } \\
\text { periodic force } \\
F_{z}(\mathrm{~N}) \\
\end{array}$ \\
\hline 1 & 300 & 0.02 & 1 & -50.32 & 92.23 & 10.73 \\
\hline 2 & 300 & 0.04 & 1 & -72.58 & 105.72 & 20.45 \\
\hline 3 & 300 & 0.06 & 1 & -96.83 & 120.34 & 53.12 \\
\hline 4 & 300 & 0.02 & 2 & -44.36 & 198.76 & 129.56 \\
\hline 5 & 300 & 0.04 & 2 & -32.88 & 237.66 & 88.92 \\
\hline 6 & 300 & 0.06 & 2 & -12.25 & 306.54 & 42.78 \\
\hline 7 & 300 & 0.02 & 3 & -1.97 & 387.25 & 2.37 \\
\hline 8 & 300 & 0.04 & 3 & 22.78 & 449.44 & -39.46 \\
\hline 9 & 300 & 0.06 & 3 & 16.57 & 586.89 & -76.83 \\
\hline
\end{tabular}

TABle 3: Cutting force coefficient.

\begin{tabular}{lccc}
\hline $\begin{array}{l}\text { Cutting force } \\
\text { parameter }\end{array}$ & $\begin{array}{c}\text { Numerical } \\
(\mathrm{Mpa})\end{array}$ & $\begin{array}{c}\text { Cutting force } \\
\text { parameter }\end{array}$ & $\begin{array}{c}\text { Numerical } \\
(\mathrm{N} / \mathrm{m})\end{array}$ \\
\hline$K_{t c}$ & 1599.8 & $K_{t e}$ & 20.7 \\
$K_{r c}$ & 520.1 & $K_{r e}$ & 42.8 \\
$K_{a c}$ & 648.2 & $K_{a e}$ & 7.9 \\
\hline
\end{tabular}

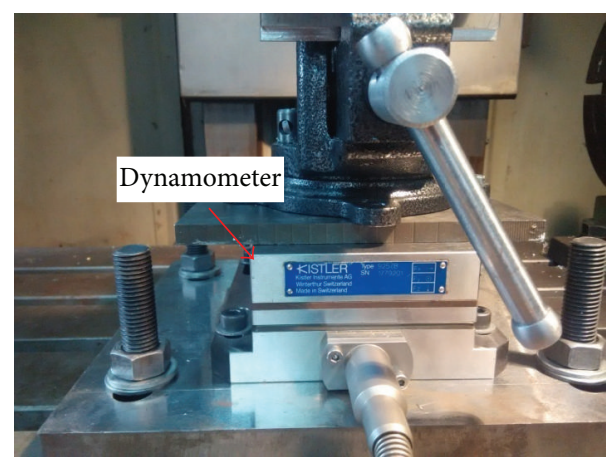

Figure 9: Kistler 9257B dynamometer.

A series of experimental data was obtained, as shown in Table 2.

From the experimental data in (17), by analyzing the relationship of cutting force, the cutting coefficient is shown in Table 3.

\section{Simulation Analysis of Ball-End Cutting Force}

5.1. Prediction and Simulation of Milling Force. The influence of cutting parameter and geometer parameter of tool on cutting forces is analyzed by turn-milling process. The ball milling cutting force is simulated based on the model of milling force by using MATLAB program in the different cutting parameters. The titanium alloy is used as workpiece material. The diameter of cutter is $10 \mathrm{~mm}$. The depth of cut is $0.5 \mathrm{~mm}$. The different cutting force simulation results are shown in Figures 10-15 as follows.

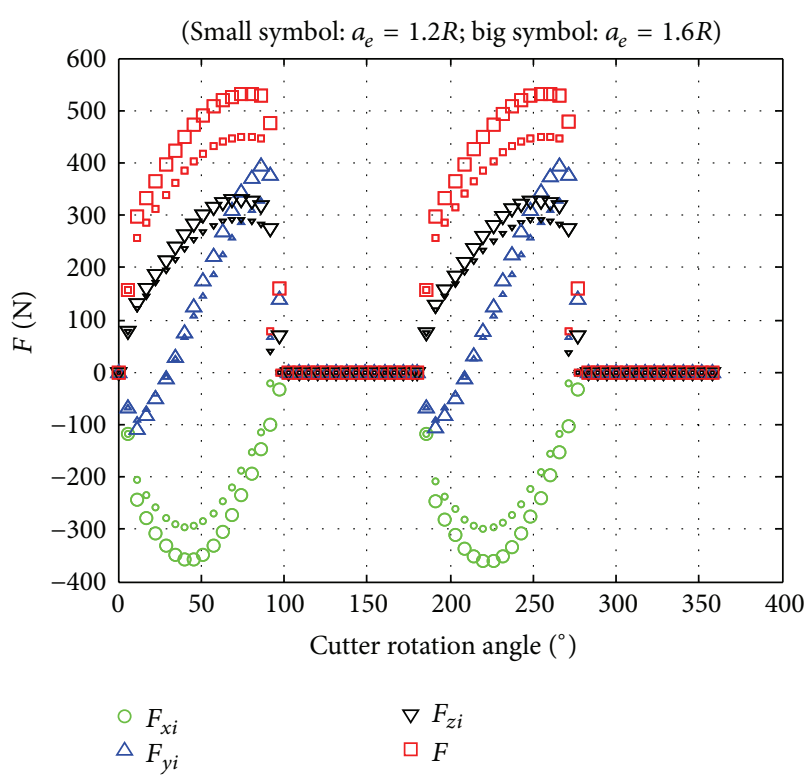

Figure 10: Effect of cutting width $a_{e}$ on cutting force.

5.1.1. The Influence of Cutting Width and Tilt Angle on Cutting Force. Similarly, when the cutting depth is reduced, cutting forces in three directions $X, Y$, and $Z$ are all decreased, where the magnitudes of decreases are relatively large, and the total cutting force becomes smaller from Figure 10. But when the cutting depth is reduced, cutting-in angle is constant while cutting-out angle becomes smaller. As can be seen from Figure 11, cutting force decreases with increasing of dip. So, the tilt angle can be increased to reduce the cutting force during processing.

5.1.2. The Influence of Tooth Number and Cutting Depth on Cutting Force. It can be noticed from Figure 12 the change of milling cutter blade has no effect on the cutting force, but it affects the numbers of milling force cycle in a rotary cutter cycle. The numbers of milling force cycle are equal to the number of milling cutter blade and entrance angle and exit angle go backwards with the increasing number of cutting edge. 


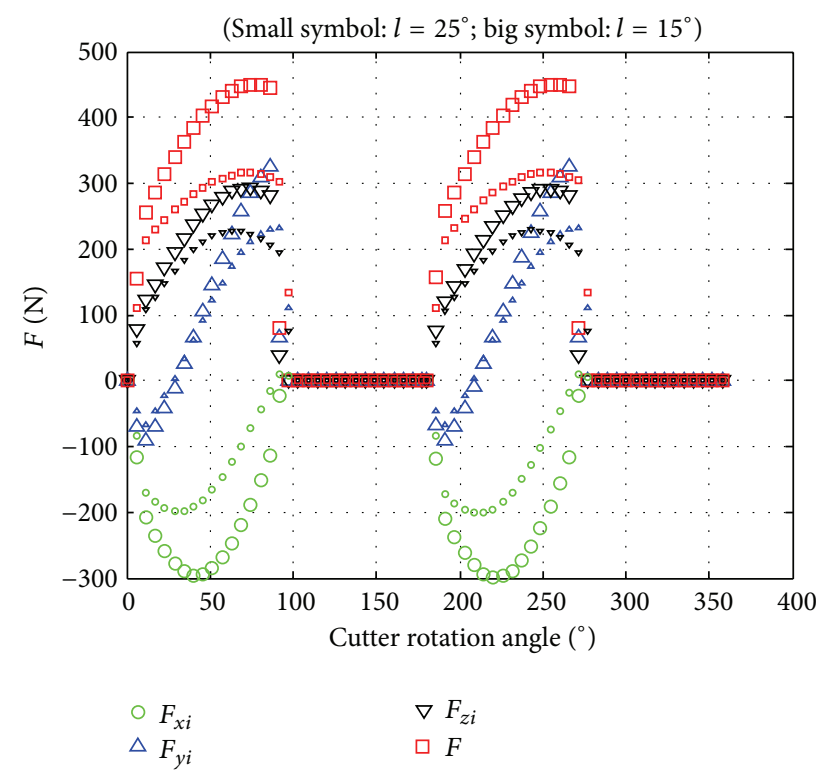

FIGURE 11: Effect of tilt angle on cutting force.

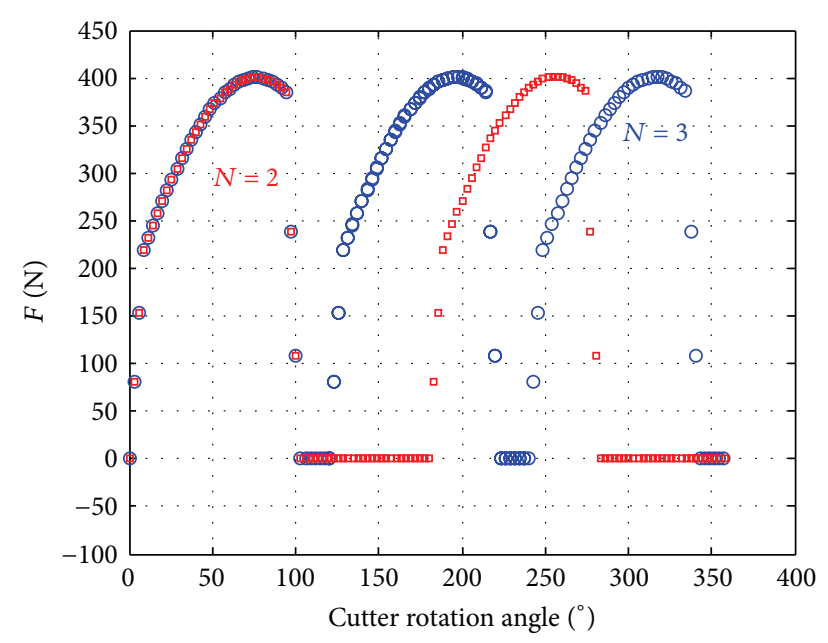

FIGURE 12: Effect of tooth number on cutting force.

When the cutting depth is reduced, cutting forces in three directions $X, Y$, and $Z$ are all decreased and the total cutting force becomes smaller from Figure 13. But when the cutting depth decreases, entrance angle and exit angle are constant.

\subsubsection{The Influence of Cutter Diameter on Cutting Force.} When focusing on the effect of cutter diameter on cutting force, the larger the cutter diameter is, the larger the cutting force becomes no matter whether it is a given value or not in Figure 14. With the change of cutter diameter, entrance angle remains unchanged while exit angle changes.

\subsubsection{The Influence of Cutter Diameter and Feed on Cutting} Force. It can be noticed from Figure 15 that cutting force and cutting-in angle are not affected by different helix angle. But the cutting-out angle will be bigger when the helix angle increases. The last parameter is the rational speed. Feed has

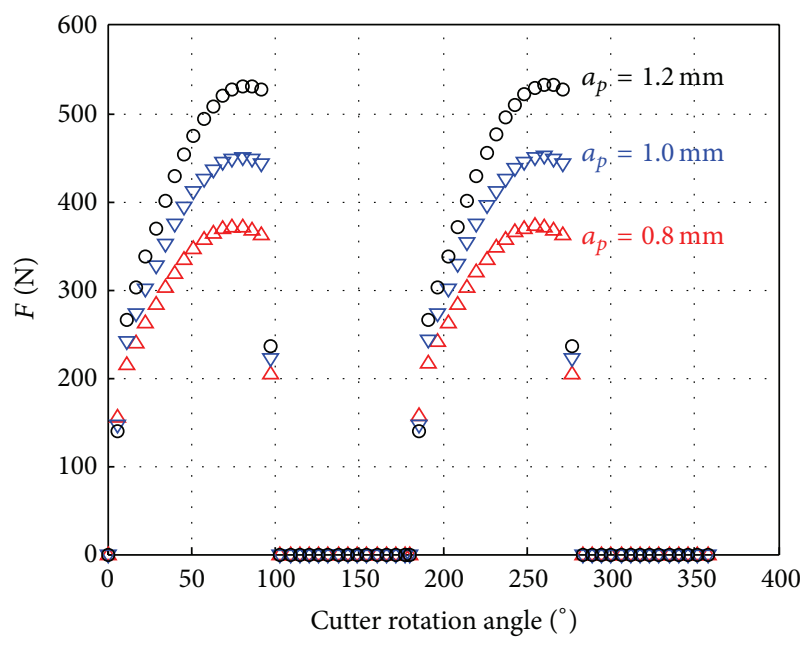

FIGURE 13: Effect of cutting depth on cutting force.

a great impact on the maximum cutting force as shown in Figure 16. And slight increase can cause large changes of the total cutting force so that the amount of feed should be selected with season during processing.

5.2. Comparison of Rigid and Flexible Cutting Force. In order to illustrate the contribution of flexible cutting force, comparison of flexible cutting forces and rigid cutting forces was simulated based on the same cutting conditions in Figure 15.

It can be seen from Figure 17 that flexible cutting force is smaller than rigid cutting force in differential direction, but the value is more by $19 \mathrm{~N}$ in the $X$ direction. Consequently, it is necessary that the flexible model of cutting force is analyzed. For the validation of the model, another simulation (in Figure 18) is conducted in the same cutting condition [24] as follows: $a_{n}=0$, spindle speed $=269 \mathrm{r} / \mathrm{min}, R_{0}=$ $9.526 \mathrm{~mm}, i_{0}=30$, st $=0.0508 \mathrm{~mm}$, and $a_{p}=6.35 \mathrm{~mm}$. The predicted cutting forces are compared and matched well with the experiment [24]. Therefore, it provides a theoretical foundation and reference for the turn-milling mechanism research.

\section{Conclusions}

In this paper, the cutting force of blade by turn-milling was studied in cutting parameters. A rigid model and a flexible model of cutting force with ball-end cutter are established, respectively, based on the analysis of space geometry of the ball-end mill and blades. Some suggestions are provided to choose cutting parameters to reduce cutting forces and reach high productivity. This study will provide a theoretical foundation and reference for the turn-milling mechanism research. Based on this work, the following conclusions can be drawn:

(i) The influences of cutting parameters and geometry shape of cutter on the cutting forces are analyzed by turn-milling. The deformation values of blade 


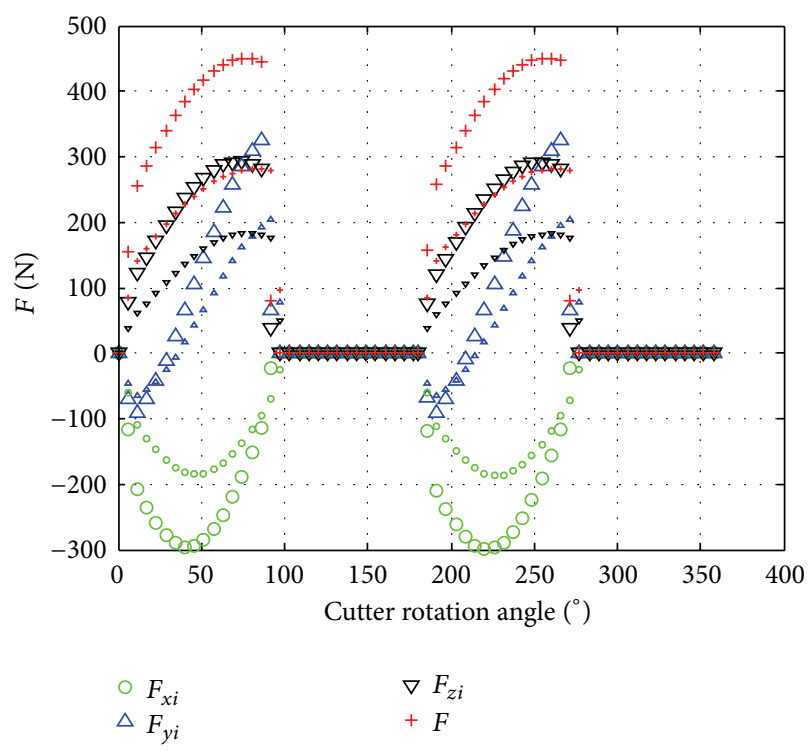

(a) $a_{e}$ is a multiple of the diameter

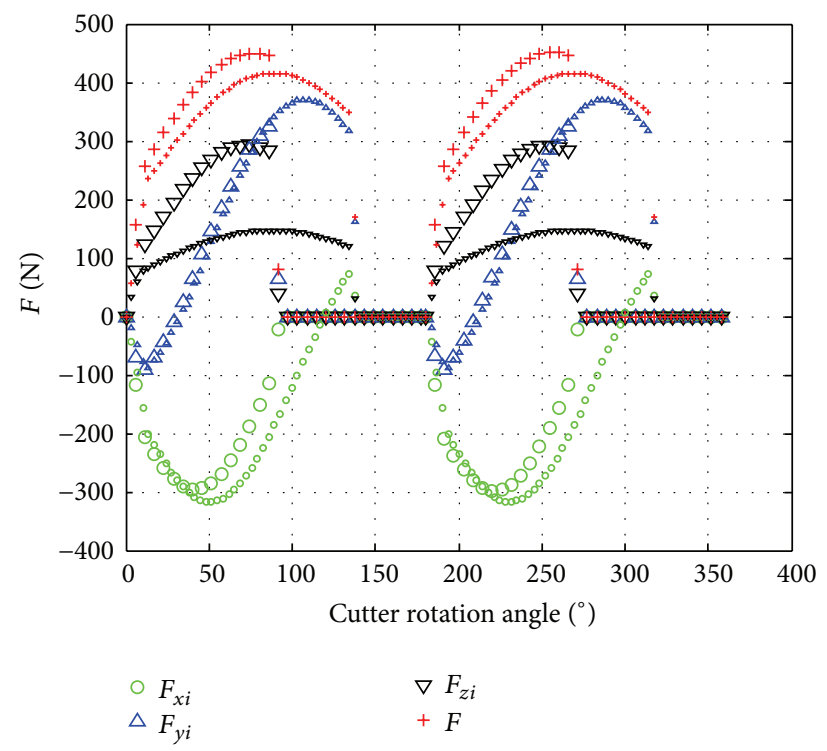

(b) $a_{e}$ is constant

FIGURE 14: Effect of cutter diameter on cutting force (big symbol: $D=8 \mathrm{~mm}$; small symbol: $D=5 \mathrm{~mm}$ ).

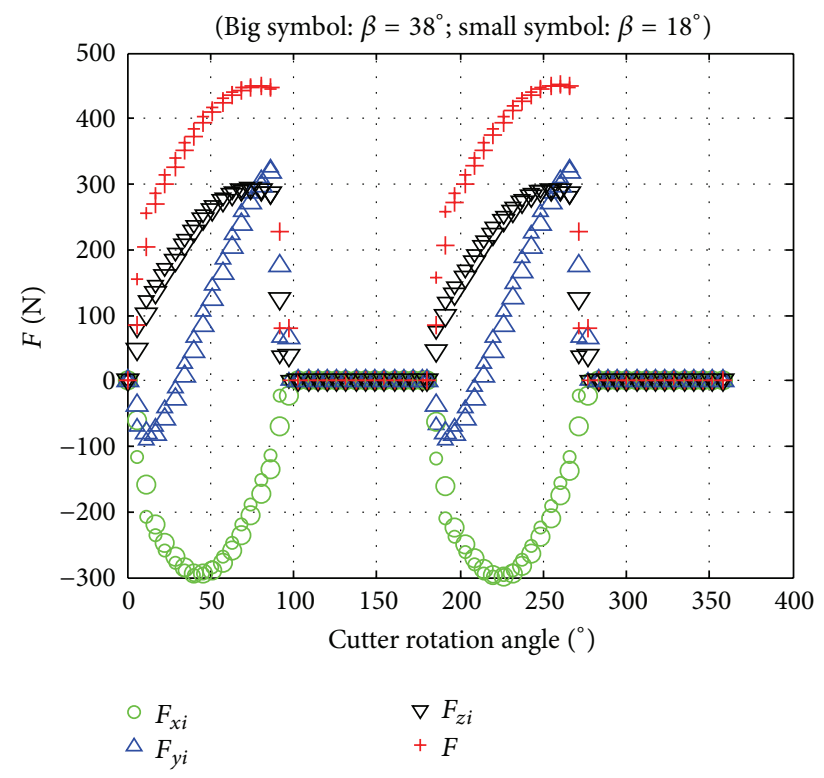

FIGURE 15: Effect of helix angle on cutting force.

and cutter on the engaged trajectory are calculated, respectively, by using the iterative algorithm.

(ii) In milling blades case, cutting force is sensitive to the amount of feed, but the influence of helix angle is the smallest. The amount of deformation of the blade will not be the same in a different thickness position of the blade. The thinner the thickness is, the greater the bending deformation becomes. And cutting force is also affected by the deformation.

(iii) In milling titanium blades case, flexible cutting force is smaller than rigid cutting force in each direction,

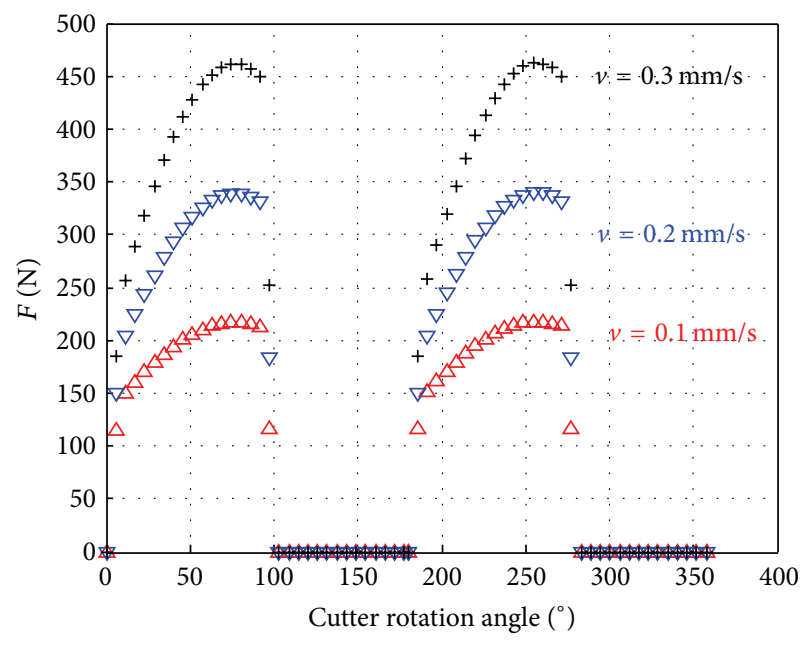

Figure 16: Effect of feed on cutting force.

but it is less $20 \mathrm{~N}$. Since stiffness of titanium alloy is relatively large, the deformation of titanium alloy is small, and deformation of the tool is of the order of -5 times.

\section{Nomenclature}

$n_{t}$ : Rotation speed of cutter $(\mathrm{r} / \mathrm{min})$

$n_{b}$ : Rotation speed of blade $(\mathrm{r} / \mathrm{min})$

$a_{p}$ : Depth of cut $(\mathrm{mm})$

$f_{z}$ : Feed per tooth $(\mathrm{mm} / z)$

$t_{c}$ : Uncut chip thickness (mm)

$v$ : Poisson ratio of blade

$\delta_{t}$ : Deflection value of tool

$\delta_{b}$ : Deflection value of blade 


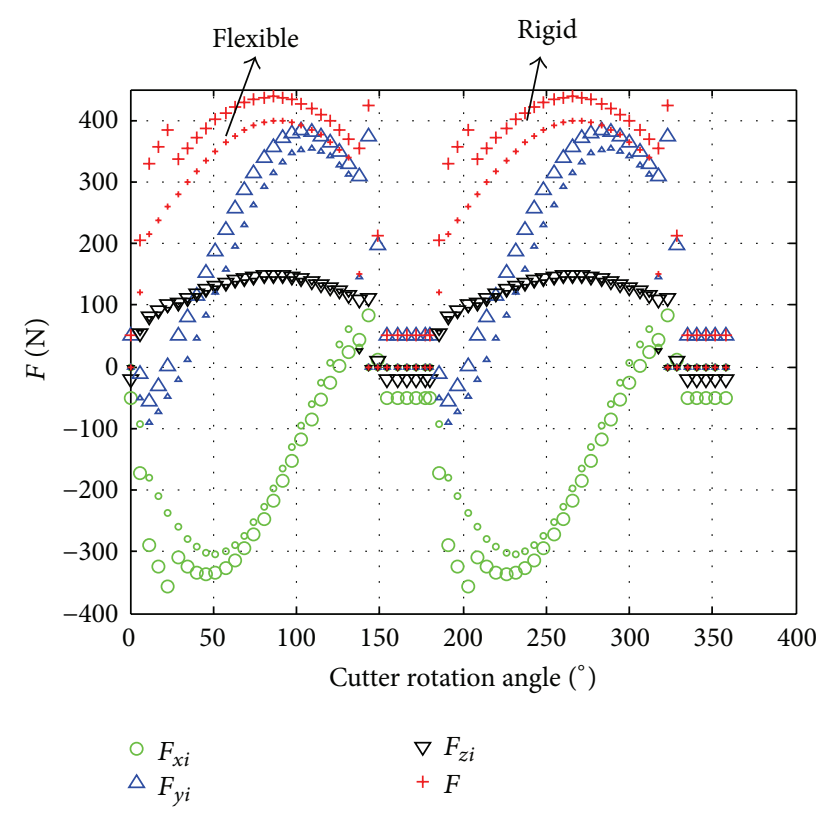

FIGURE 17: Comparisons of cutting forces in flexible and rigid model.

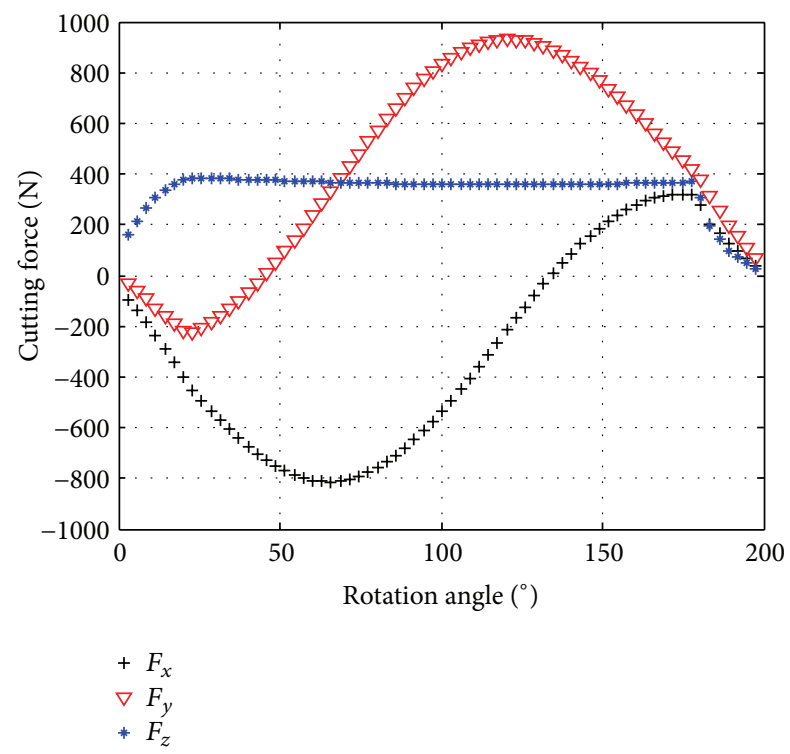

FIGURE 18: Simulated cutting forces in end milling.

$$
\begin{array}{ll}
\delta_{w}: & \text { Cutter bending deflection } \\
\delta_{c}: & \text { Clamping deflection } \\
K_{r c}, K_{a c}, \text { and } K_{t c}: & \text { Radial, axial, and tangential cutting force } \\
& \text { coefficients } \\
K_{r e}, K_{a e}, \text { and } K_{t e}: & \text { Edge force coefficients } \\
\psi: & \text { Immersion angle of cutting point } \\
\phi: & \text { Cutting element position angle } \\
\beta: & \text { Angle between the } Y \text {-axis and the } \\
\theta: & \text { reference cutting flute } \\
& \text { Angle between the cross-feed direction } \\
K_{c}: & \text { and the cutting flute } \\
r: & \text { Measured clamping stiffness of cutter }
\end{array}
$$

$z$ : The number of teeth on the cutter

$f_{a}$ : Axial feed $(\mathrm{mm} / \mathrm{r})$

$f_{r}$ : Radial feed $(\mathrm{mm} / \mathrm{r})$

$E$ : Elastic modulus of blade

$h$ : Thickness of blade

$e_{t b}:$ Surface error

$a_{e}$ : Radial depth of cut.

\section{Competing Interests}

The authors declare that there are no competing interests regarding the publication of this paper.

\section{Acknowledgments}

This work was supported by the National Natural Science Foundation of China (NSFC) (51105072 and 51475087), supported by the Fundamental Research Funds for the Central Universities (N150304005).

\section{References}

[1] U. Karaguzel, M. Bakkal, and E. Budak, "Process modeling of turn-milling using analytical approach," Procedia CIRP, vol. 4, pp. 131-139, 2012.

[2] U. Karagüzel, E. Uysal, E. Budak, and M. Bakkal, "Analytical modeling of turn-milling process geometry, kinematics and mechanics," International Journal of Machine Tools \& Manufacture, vol. 91, pp. 24-33, 2015.

[3] S. Ekinovic, E. Begovic, and A. Silajdzija, "Comparison of machined surface quality obtained by high-speed machining and conventional turning," Machining Science and Technology, vol. 11, no. 4, pp. 531-551, 2007.

[4] S. Škorić, T. Udiljak, and D. Ciglar, "Study of the suitability of the machining of rotating surfaces," Transactions of Famena, vol. 32, no. 2, pp. 69-83, 2008.

[5] M. Pogacnik and J. Kopac, "Dynamic stabilization of the turnmilling process by parameter optimization," Proceedings of the Institution of Mechanical Engineers, Part B, vol. 214, no. 2, pp. 127-135, 2000.

[6] S. K. Choudhury and J. B. Bajpai, "Investigation in orthogonal turn-milling towards better surface finish," Journal of Materials Processing Technology, vol. 170, no. 3, pp. 487-493, 2005.

[7] S. K. Choudhury and K. S. Mangrulkar, "Investigation of orthogonal turn-milling for the machining of rotationally symmetrical work pieces," Journal of Materials Processing Technology, vol. 99, no. 1, pp. 120-128, 2000.

[8] A. Calleja, A. Fernandez, A. Rodriguez, L. N. de Lacalle, and A. Lamikiz, "Turn-milling of blades in turning centres and multitasking machines controlling tool tilt angle," Proceedings of the Institution of Mechanical Engineers, Part B: Journal of Engineering Manufacture, vol. 229, no. 8, pp. 1324-1336, 2015.

[9] C. M. Lee, S. W. Kim, Y. H. Lee, and D. W. Lee, “The optimal cutter orientation in ball end milling of cantilever-shaped thin plate," Journal of Materials Processing Technology, vol. 153-154, pp. 900-906, 2004.

[10] M. Fontaine, A. Moufki, A. Devillez, and D. Dudzinski, "Modelling of cutting forces in ball-end milling with tool-surface inclination. Part I: predictive force model and experimental validation," Journal of Materials Processing Technology, vol. 189, no. 1-3, pp. 73-84, 2007. 
[11] D. Biermann, P. Kersting, and T. Surmann, "A general approach to simulating workpiece vibrations during five-axis milling of turbine blades," CIRP Annals-Manufacturing Technology, vol. 59, no. 1, pp. 125-128, 2010.

[12] I. Lazoglu, Y. Boz, and H. Erdim, "Five-axis milling mechanics for complex free form surfaces," CIRP Annals-Manufacturing Technology, vol. 60, no. 1, pp. 117-120, 2011.

[13] E. Budak, E. Ozturk, and L. T. Tunc, "Modeling and simulation of 5-axis milling processes," CIRP Annals-Manufacturing Technology, vol. 58, no. 1, pp. 347-350, 2009.

[14] E. Budak, "Improving 5-axis milling operations using process models," MM Science Journal, pp. 358-365, 2012.

[15] E. Ozturk and E. Budak, "Dynamics and stability of fiveaxis ball-end milling," Journal of Manufacturing Science and Engineering, vol. 132, no. 2, 2010.

[16] E. Ozturk, L. T. Tunc, and E. Budak, "Investigation of lead and tilt angle effects in 5-axis ball-end milling processes," International Journal of Machine Tools \& Manufacture, vol. 49, no. 14, pp. 1053-1062, 2009.

[17] E. Budak, A. Comak, and E. Öztürk, "Stability and high performance machining conditions in simultaneous milling," CIRP Annals-Manufacturing Technology, vol. 62, no. 1, pp. 403-406, 2013.

[18] S. Herranz, F. J. Campa, L. N. L. De Lacalle et al., "The milling of airframe components with low rigidity: a general approach to avoid static and dynamic problems," Proceedings of the Institution of Mechanical Engineers Part B: Journal of Engineering Manufacture, vol. 219, no. 11, pp. 789-801, 2005.

[19] D. Olvera, L. N. L. de Lacalle, F. I. Compeán, A. Fz-Valdivielso, A. Lamikiz, and F. J. Campa, "Analysis of the tool tip radial stiffness of turn-milling centers," The International Journal of Advanced Manufacturing Technology, vol. 60, no. 9, pp. 883-891, 2012.

[20] A. Lamikiz, L. N. López de Lacalle, O. Ocerin, D. Díez, and E. Maidagan, "The Denavit and Hartenberg approach applied to evaluate the consequences in the tool tip position of geometrical errors in five-axis milling centres," The International Journal of Advanced Manufacturing Technology, vol. 37, no. 1, pp. 122-139, 2008.

[21] G. M. Kim, B. H. Kim, and C. N. Chu, "Estimation of cutter deflection and form error in ball-end milling processes," International Journal of Machine Tools and Manufacture, vol. 43, no. 9, pp. 917-924, 2003.

[22] E. B. Kivanc and E. Budak, "Structural modeling of end mills for form error and stability analysis," International Journal of Machine Tools \& Manufacture, vol. 44, no. 11, pp. 1151-1161, 2004.

[23] Q. Cao, J. Zhao, S. Han, and X. Chen, "Force coefficients identification considering inclination angle for ball-end finish milling," Precision Engineering, vol. 36, no. 2, pp. 252-260, 2012.

[24] P. Lee and Y. Altintaş, "Prediction of ball-end milling forces from orthogonal cutting data," International Journal of Machine Tools and Manufacture, vol. 36, no. 9, pp. 1059-1072, 1996. 

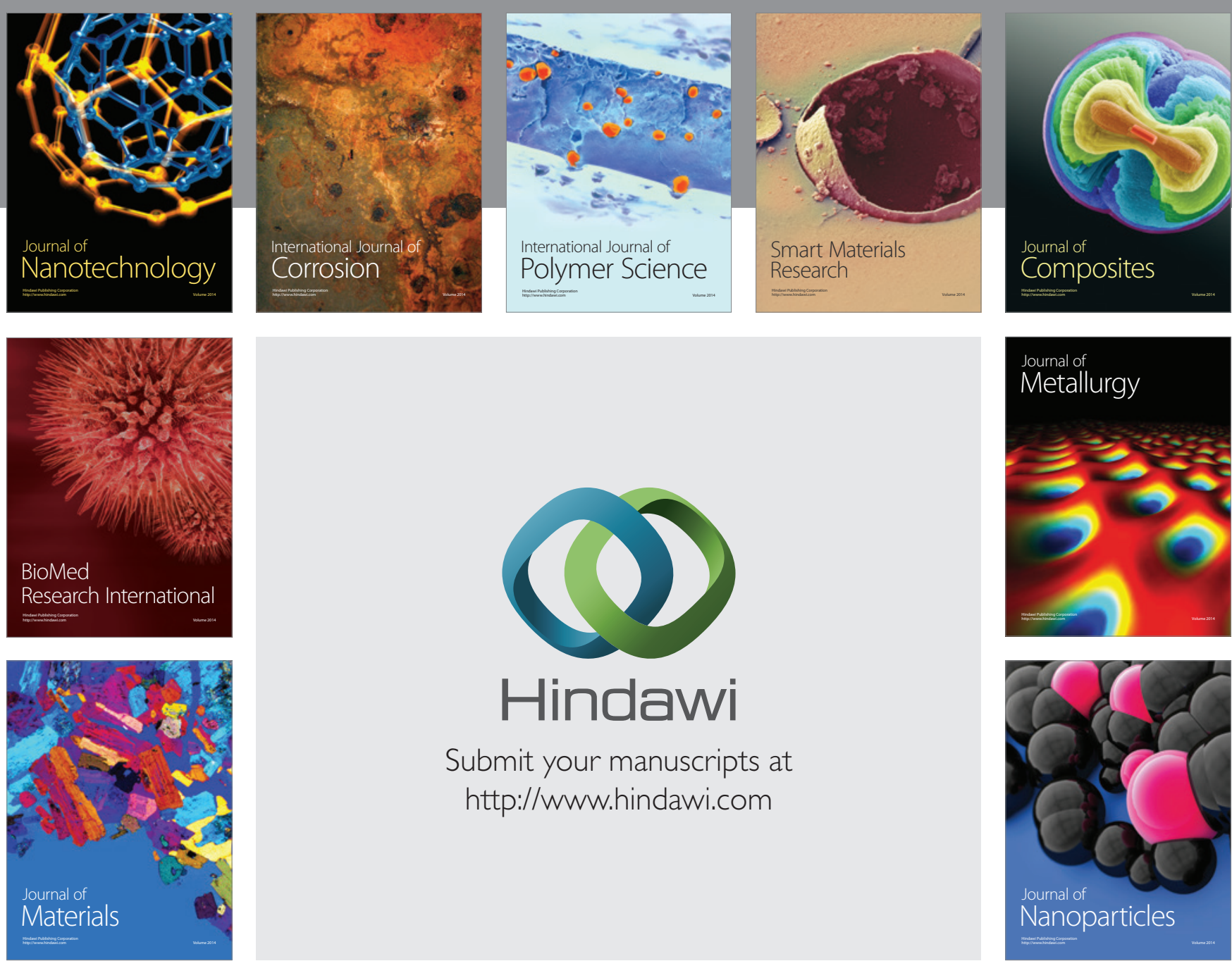

\section{Hindawi}

Submit your manuscripts at

http://www.hindawi.com

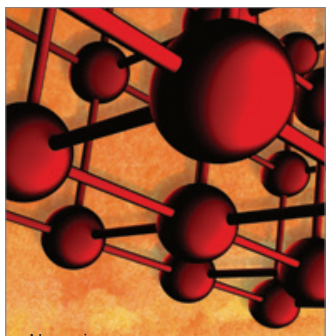

Materials Science and Engineering
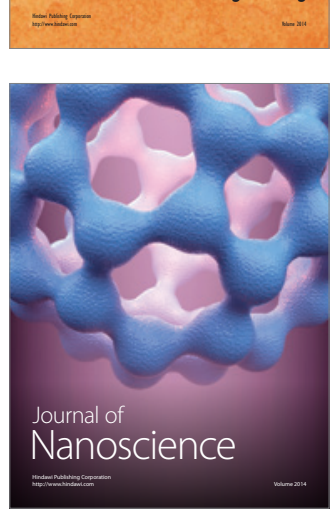
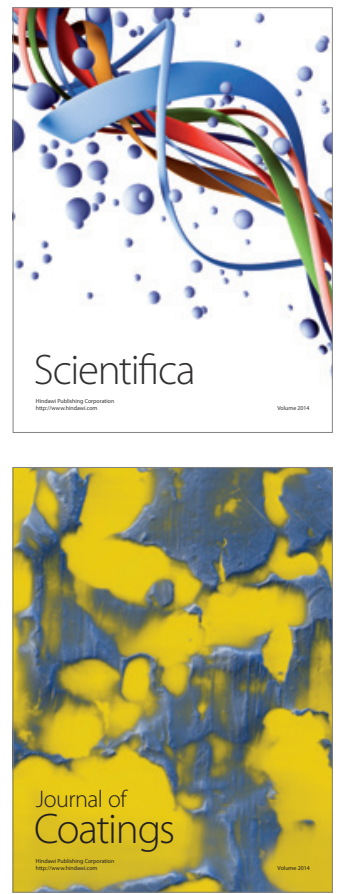
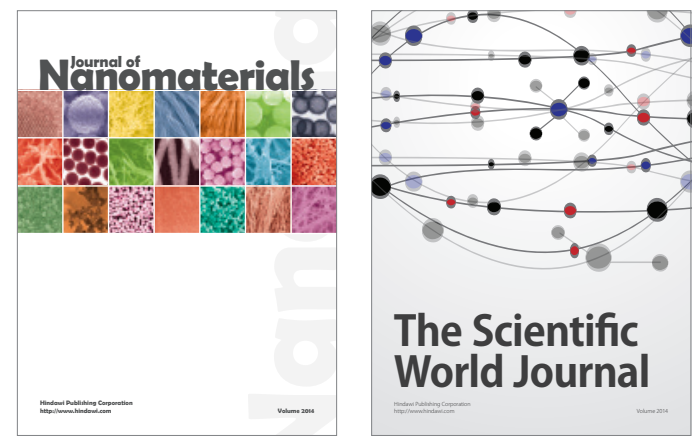

The Scientific World Journal
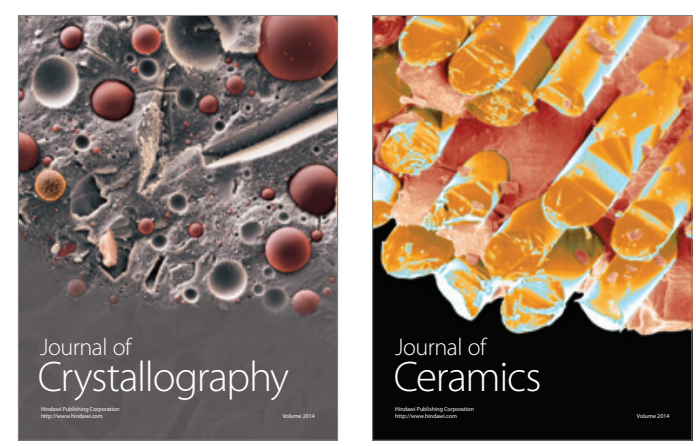
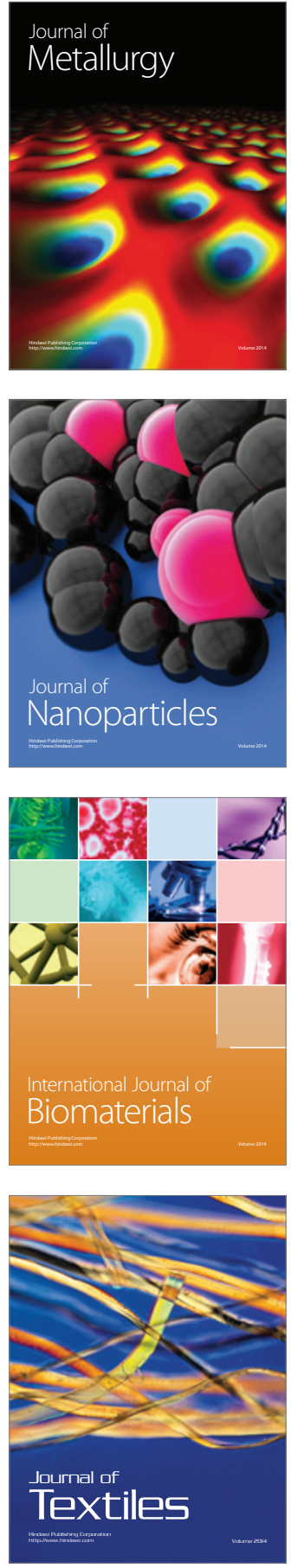